\title{
Study of the Role of Anti-Cancer Molecules with Different Sizes for Decreasing Corresponding Bulk Tumor Multiple Organs or Tissues
}

\section{A Heidari}

Faculty of Chemistry, California South University, 14731 Comet St. Irvine, CA 92604, USA

Corresponding author: A Heidari, Faculty of Chemistry, California South University (CSU), 14731 Comet St. Irvine, CA 92604, USA, Tel: 1-775-410-4974; E-mail: Scholar.Researcher.Scientist@gmail.com

Received: 09 June 2016; Accepted: 20 June 2016; Published: 23 June 2016

Citation: Heidari A. Study of the Role of Anti-Cancer Molecules with Different Sizes for Decreasing Corresponding Bulk Tumor Multiple Organs or Tissues. Arch Can Res. 2016, 4: 2.

\section{Commentary}

The intermolecular forces between anti-cancer molecules such as Cisplatin, Carboplatin, Oxaliplatin, Nedaplatin, Lobaplatin, Heptaplatin, Dicycloplatin, Eleutherobin, Epothilone B, Discodermolide and Taxol (Figures 1 and 2) and tumor multiple organs or tissues are of great importance in many areas of science including medicine, chemotherapy, pharmacology, medicinal chemistry, pharmaceutical chemistry, biochemistry and so on [1-21]. As a result, these molecular systems have received a great significant of attention in both computational and theoretical aspects [22-32]. In this commentary, all calculations are carried out by Gaussian 09. Geometry optimization for each molecule are be fulfilled at $\mathrm{HF}$, PM3, MM2, MM3, AM1, MP2, MP3, MP4, CCSD, CCSD(T), LDA, BVWN, BLYP and B3LYP computational methods with 31G, 6$31 G^{*}, 6-31+G^{*}, 6-31 \mathrm{G}(3 \mathrm{df}, 3 \mathrm{pd}), 6-311 \mathrm{G}, 6-311 \mathrm{G}^{*}$ and 6$311+\mathrm{G}^{*}$ basis sets, respectively. It should be noted that calculations are accomplished at $298 \mathrm{~K}$ and $0 \mathrm{~K}$ at HF, PM3, MM2, MM3, AM1, MP2, MP3, MP4, CCSD, CCSD(T), LDA, BVWN, BLYP and B3LYP computational methods with 31G, 6$31 G^{*}, 6-31+G^{*}, 6-31 G(3 d f, 3 p d), 6-311 G, 6-311 G^{*}$ and 6$311+G^{*}$ basis sets, respectively. Also, the spectroscopic, structural and thermodynamic properties were investigated.

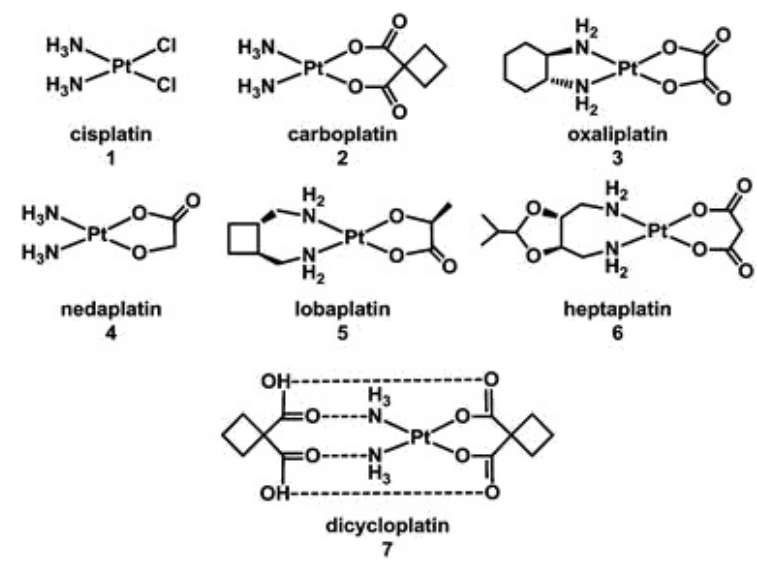

Figure 1 Molecular structures of Cisplatin, Carboplatin, Oxaliplatin, Nedaplatin, Lobaplatin, Heptaplatin and Dicycloplatin anti-cancer molecules.

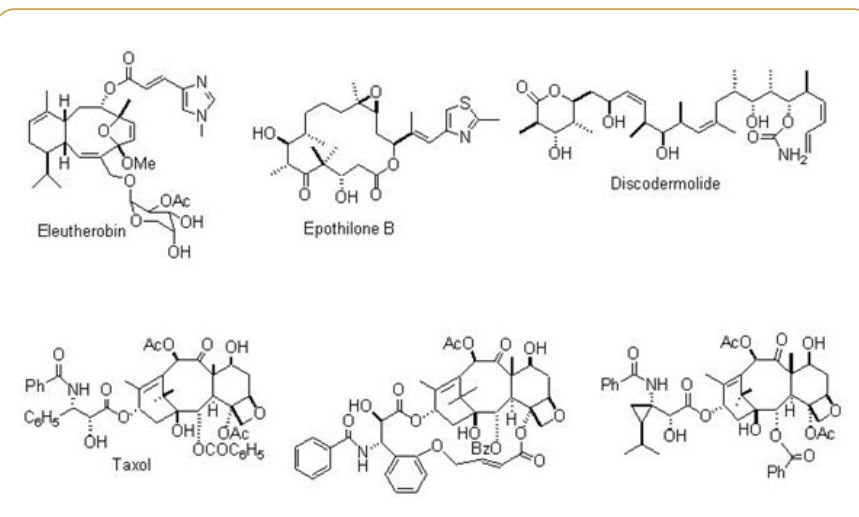

Figure 2 Molecular structures of Eleutherobin, Epothilone B, Discodermolide and Taxol anti-cancer molecules.

On the other hand, chemical behavior of Cisplatin, Carboplatin, Oxaliplatin, Nedaplatin, Lobaplatin, Heptaplatin, Dicycloplatin, Eleutherobin, Epothilone B, Discodermolide and Taxol as anti-cancer molecules has been investigated very extensively because of their importance in chemical and biological systems. Furthermore, study of Cisplatin, Carboplatin, Oxaliplatin, Nedaplatin, Lobaplatin, Heptaplatin, Dicycloplatin, Eleutherobin, Epothilone B, Discodermolide and Taxol as anti-cancer molecules with different sizes can help to understand how anti-cancer molecules bulk limit as the tumor size decreases. Due to the complexity of the interaction of Cisplatin, Carboplatin, Oxaliplatin, Nedaplatin, Lobaplatin, Heptaplatin, Dicycloplatin, Eleutherobin, Epothilone B, Discodermolide and Taxol as anti-cancer molecules which is dominated by the Hydrogen bonding, the chemical structures of Cisplatin, Carboplatin, Oxaliplatin, Nedaplatin, Lobaplatin, Heptaplatin, Dicycloplatin, Eleutherobin, Epothilone B, Discodermolide and Taxol as anti-cancer molecules are complex and difficult. In this commentary, all calculations are carried out by Gaussian 09. Geometry optimization for each anti-cancer molecule is carried out at $\mathrm{HF}, \mathrm{PM} 3, \mathrm{MM} 2, \mathrm{MM} 3$, AM1, MP2, MP3, MP4, CCSD, CCSD(T), LDA, BVWN, BLYP and B3LYP computational methods with 31G, 6-31G*, 6-31+G*, 631G(3df, 3pd), 6-311G, 6-311G* and 6-311+G* basis sets, respectively. In addition, calculations are accomplished at 298K and $\mathrm{OK}$ at HF, PM3, MM2, MM3, AM1, MP2, MP3, MP4, $\operatorname{CCSD}, \operatorname{CCSD}(T), L D A, B V W N, B L Y P$ and B3LYP computational 
methods with $31 \mathrm{G}, 6-31 \mathrm{G}^{*}, 6-31+\mathrm{G}^{*}, 6-31 \mathrm{G}(3 \mathrm{df}, 3 \mathrm{pd})$, 6311G, 6-311G* and $6-311+G^{*}$ basis sets, respectively. Moreover, the spectroscopic, structural and thermodynamic properties were studied.

Furthermore, Cadmium Oxide ( $\mathrm{CdO}$ ) nanoparticles are used as anti-cancer Nano drugs. They make a strong complex with DNA/RNA of human cancer cells which in human metabolism complexes have vital role. Each Nano compound or Nano material that perturbs the structure and normal reactivity of a vital complex is named a position. A position is either a strong ligand which makes a complex with DNA/RNA of human cancer cells and/or a metal which can react with vital ligands. In medicinal, pharmaceutical, clinical and biochemical approaches, a strong DNA/RNA of human cancer cells ligand applies to remove the metal position. Theoretically, computationally and experimentally, as much a complex is more stable its anti-cancer properties should be stronger. This stability depends on conformational stability of DNA/RNA of human cancer cells ligands. Based on these principles, we have introduced some anti-cancer Nano drugs such as Cadmium Oxide ( $\mathrm{CdO}$ ) nanoparticles and consider their stability energies in complex making with DNA/RNA of human cancer cells. Our results showed that some nanoparticles such as Cadmium Oxide ( $\mathrm{CdO})$ nanoparticles could be theoretically, computationally and experimentally used as anti-cancer Nano drugs. We have also reported their preparation procedure and we have studied the role of stereochemistry in these anticancer Nano drugs. By these types of calculations, we have also introduced some nucleic acids complexes as good anticancer Nano drugs using Gaussian 09 at HF, PM3, MM2, MM3, AM1, MP2, MP3, MP4, CCSD, CCSD(T), LDA, BVWN, BLYP and B3LYP computational methods with 31G, 6-31G*, 6-31+G*, 6$31 \mathrm{G}(3 \mathrm{df}, 3 \mathrm{pd}), 6-311 \mathrm{G}, 6-311 \mathrm{G} *$ and $6-311+\mathrm{G}^{*}$ basis sets, respectively. In this commentary, we would like to extend our studies about stereochemistry of some roles of anti-cancer molecules with different sizes for decreasing corresponding bulk tumor multiple organs or tissues.

\section{References}

1. Weiping $L$, Jing J, Chengying $X$, Shuqian $H$, Haitian $Q$, et al. (2014) Synthesis, anticancer activity and toxicity of a watersoluble $4 \mathrm{~S}, 5 \mathrm{~S}$-derivative of heptaplatin, cis-\{Pt(II)[(4S,5S)-4,5bis(aminomethyl)-2-isopropyl-1,3-dioxolane]·(3-hydroxylcyclobutane-1,1-dicarboxylate)\}. Journal of Inorganic Biochemistry 140: 126-130.

2. Takumi S, Terukazu N, Masakatsu O, Takashi U, Hiroyuki N, et al. (2016) PD34-06 salvage chemotherapy with paclitaxel, ifosfamide and nedaplatin (tin) for refractory or relapsed germ cell tumors in patients with impaired renal function. The Journal of Urology 195: e841.

3. Masatomo N, Hideaki M, Masato F (2016) MP81-20 Irinotecan and nedaplatin as salvage therapy for patients with advanced germ cell tumor following intensive treatment with cisplatinbased combination chemotherapies. The Journal of Urology 195: 1060 .

4. Katsuyuki T, Masako T, Masakazu Y, Masaki M, Asuka O, et al. (2016) Protection of stromal cell-derived factor 2 by heat shock protein 72 prevents oxaliplatin-induced cell death in oxaliplatinresistant human gastric cancer cells. Cancer Letters 378: 8-15.

5. Yu Z, Qiang L, Junfeng W, Fang C, Xiao H, et al. (2016) Polysaccharide from Lentinus edodes combined with oxaliplatin possesses the synergy and attenuation effect in hepatocellular carcinoma. Cancer Letters 377: 117-125.

6. Toshiaki S, Keisuke M, Naomi Y, Mayuko S, Akina K, et al. (2016) Processed aconite root and its active ingredient neoline may alleviate oxaliplatin-induced peripheral neuropathic pain. Journal of Ethnopharmacology 186: 44-52.

7. Kenneth KW, Daniel CP, Yuming W, Fang W, Ge L, et al. (2016) Data showing the circumvention of oxaliplatin resistance by vatalanib in colon cancer. Data in Brief 7: 437-444.

8. Walter T, Planchard D, Bouledrak K, Scoazec JY, Souquet PJ, et al. (2016) Evaluation of the combination of oxaliplatin and 5fluorouracil or gemcitabine in patients with sporadic metastatic pulmonary carcinoid tumors. Lung Cancer 96: 68-73.

9. Shizuka M, Tsugunobu A, Takayuki Y, Yasushi K (2016) Involvement of c-Myc-mediated transient receptor potential melastatin 8 expression in oxaliplatin-induced cold allodynia in mice. Pharmacological Reports 68: 645-648.

10. Wey-Ran L, Jy-Ming C, Chau-Ting Y (2016) Su2007 GALNT14 genotype predicts postoperative outcome of stage III colorectal cancer with oxaliplatin as adjuvant chemotherapy. Gastroenterology 150: S609.

11. Lorenzo DCM, Matteo Z, Ida L, Alessandra P, Carla G, et al. (2016) Effect of the SOD mimetic MnL4 on in vitro and in vivo oxaliplatin toxicity: Possible aid in chemotherapy induced neuropathy. Free Radical Biology and Medicine 93: 67-76.

12. Zhao J, Rensen S, Vreuls C, Broek MVD, Jetten M, et al. (2016) miR-21 and miR-150 down regulation correlates with oxaliplatin-related sinusoidal obstruction syndrome and impaired survival. HPB 18: e135.

13. Bednarsch J, Jara M, Malinowski M, Pratschke J, Stockmann M (2016) Effects of oxaliplatin-based chemotherapy on actual liver function capacity. HPB 18: e827.

14. Wakiya T, Kudo D, Toyoki Y, Ishido K, Kimura N, et al. (2016) Effect of bevacizumab on the development of oxaliplatinassociated liver injury in colorectal cancer liver metastasis. HPB 18: e183.

15. Zhimei W, Mian W, Shaohua G (2016) Toward a better understanding of the oxaliplatin mode of action upon the steric hindrance of 1,2-diaminocyclohexane and its analogue. Journal of Inorganic Biochemistry 157: 1-7.

16. Shohei Y, Hideki O, Kazuhiko K, Masahiro O (2016) Oxaliplatin treatment changes the function of sensory nerves in rats. Journal of Pharmacological Sciences 130: 189-193.

17. Verônica FA, Francine CC, Alencar KM, Maiquidieli DB, Fernanda $B$, et al. (2016) Superoxide-hydrogen peroxide imbalance interferes with colorectal cancer cells viability, proliferation and oxaliplatin response. Toxicology in vitro 32: 8-15.

18. Christoph S, Karin O, Anja L, Annette D, Marcus H, et al. (2016) Efficacy and safety of gemcitabine, oxaliplatin, and paclitaxel in cisplatin-refractory germ cell cancer in routine care-Registry data from an outcomes research project of the German Testicular Cancer Study Group. Urologic Oncology: Seminars and Original Investigations 34: 168.e21-168.e28.

19. Sangeetha MR, Maxwell TV, Judith AP, Nancy K, Irene BH, et al. (2016) Quantitative sensory testing at baseline and during cycle 
1 oxaliplatin infusion detects subclinical peripheral neuropathy and predicts clinically overt chronic neuropathy in gastrointestinal malignancies. Clinical Colorectal Cancer 15: 37-46.

20. Juraj Z, Hana K, Vojtech N, Oldrich V, Raji R, et al. (2016) Potentiation of mitochondrial dysfunction in tumor cells by conjugates of metabolic modulator dichloroacetate with a Pt(IV) derivative of oxaliplatin. Journal of Inorganic Biochemistry 156: 89-97.

21. White S, Park W, Kim D, Larson A (2016) Magnetically triggered oxaliplatin release for the treatment of colorectal liver metastasis: an in vitro feasibility study. Journal of Vascular and Interventional Radiology 27: S23.

22. Xiubing Z, Pan X, Wenkai N, Hui F, Jian X, et al. (2016) Downregulated DYRK2 expression is associated with poor prognosis and Oxaliplatin resistance in hepatocellular carcinoma. Pathology - Research and Practice 212: 162-170.

23. Ayumi S, Tsugunobu A, Yasushi K (2016) Involvement of mast cells and proteinase-activated receptor 2 in oxaliplatin-induced mechanical allodynia in mice. Pharmacological Research 105: 84-92.

24. Ji-Hee $\mathrm{Y}$, Seo-Yeon Y, Soon-Keun K, Sol-Ji K, Jang-Hern L, et al. (2016) Repetitive acupuncture point treatment with diluted bee venom relieves mechanical allodynia and restores intraepidermal nerve fiber loss in oxaliplatin-induced neuropathic mice. The Journal of Pain 17: 298-309.

25. Lopez-Gonzalez $P$, Madrigal-Burgaleta $R$, Berges-Gimeno $P$, Solano-Solares E, Carpio-Escalona L, et al. (2016) Diagnostic tests in hypersensitivity to oxaliplatin beyond clinical history. Journal of Allergy and Clinical Immunology 137: AB36.
26. Ken Y, Mayuko T, Toshie K, Kenji A, Yoshihiko N, et al. Oxaliplatin administration increases expression of the voltage-dependent calcium channel $\alpha 2 \delta-1$ subunit in the rat spinal cord. Journal of Pharmacological Sciences 130: 117-122.

27. Shengchao L, Kecheng L, Wenpei D, Liyan Y, Haiyang S, et al. (2016) Enhancement of oxaliplatin sensitivity in human colorectal cancer by hypericin mediated photodynamic therapy via ROS-related mechanism. The International Journal of Biochemistry \& Cell Biology 71: 24-34.

28. Veer ET, Oijen MGHV, Laarhoven HWMV (2016) S-1 with leucovorin and oxaliplatin for advanced gastric cancer. The Lancet Oncology 17: e41.

29. Da Z, Jianqiang Z, Kunming J, Ke L, Yangwei C, et al. (2016) Preparation, characterisation and antitumour activity of $\beta-, \gamma-$ and HP- $\beta$-cyclodextrin inclusion complexes of oxaliplatin. Spectrochimica Acta Part A: Molecular and Biomolecular Spectroscopy 152: 501-508.

30. Yi K, Chunping G, Desheng Z, Xuyan Z, Qinghuan L, et al. (2016) Celecoxib antagonizes the cytotoxicity of oxaliplatin in human esophageal cancer cells by impairing the drug influx. European Journal of Pharmaceutical Sciences 81: 137-148.

31. Jiang SP, Zhang ZD, Kang LM, Wang QH, Zhang L, et al. (2016) Celecoxib reverts oxaliplatin-induced neuropathic pain through inhibiting PI3K/Akt2 pathway in the mouse dorsal root ganglion. Experimental Neurology 275: 11-16.

32. Shuichi $H$, Naotoshi $S$, Kensei $Y$, Toshikazu M, Yoshito $K$, et al. (2016) S-1 plus leucovorin versus S-1 plus leucovorin and oxaliplatin versus S-1 plus cisplatin in patients with advanced gastric cancer: a randomised, multicentre, open-label, phase 2 trial. The Lancet Oncology 17: 99-108. 